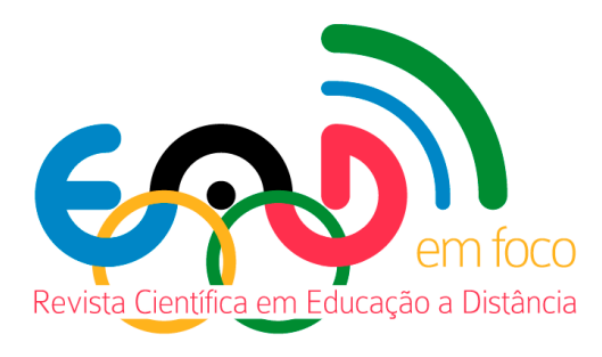

\title{
Um Breve Panorama sobre o Design Instrucional
}

\author{
Rommulo Mendes Carvalho Barreiro ${ }^{1}$
}

\footnotetext{
${ }^{1}$ Designer instrucional, Centro de Tecnologia da Indústria Química e Têxtil - SENAI/CETIQT. Rua Magalhães Castro, 174 - Rio de Janeiro-RJ - Brasil. rommulobarreiro@gmail.com
}

\section{Resumo}

O design instrucional é uma metodologia de trabalho dedicada aos processos de análise, desenho, desenvolvimento, implementação e avaliação de cursos a distância. Aplica-se desde o momento da concepção da oferta formativa até a sua implementação, direcionando seus esforços, com maior ênfase, na produção dos materiais instrucionais. A presente pesquisa visa oferecer um breve panorama acerca da função e das potencialidades do design instrucional e contribuir para o melhor entendimento sobre as ações de planejamento, execução e produção de materiais didáticos e cursos em EaD. Observa-se que o profissional apto ao trabalho com design instrucional necessita de formação ampla, que englobe habilidades de áreas como Comunicação, Design, Gestão de Processos e Pessoas, Pedagogia e Tecnologia da Informação. Como suporte à metodologia, auxiliando as tomadas de decisão dentro do projeto, existe uma documentação específica para as ações de design instrucional, tais como: roteiro, storyboard, matriz instrucional, projeto instrucional.

Palavras-chave: Design instrucional, Projeto instrucional, Matriz instrucional, Modelo ADDIE, Material didático. 


\title{
A Brief Overview of the Instructional Design
}

\begin{abstract}
The Instructional Design is a working methodology devoted to process of analysis, design, development, implementation and evaluation of e-learning. It may be applied from the moment of conception of the training offer to its implementation, directing their efforts on the production of instructional materials. This research aims to provide a brief overview of the role and potential of Instructional Design and contribute to a better understanding of the action of planning, execution and production of teaching materials and e-learning courses. The professional able to work with Instructional Design requires a broad formation, encompassing areas such as communication skills, Design, Processes and People Management, Education and Information Technology. Specific documentation for the actions of Instructional Design aid decision-making within the course creation process. These documents can be: script, storyboard, instructional matrix, instructional design, among others.
\end{abstract}

Keywords: Instructional design, Instructional project, Instructional matrix, ADDIE model, Didactic material. 


\section{Introdução}

Do final do século XX aos dias de hoje, a sociedade vem experimentando novos meios de disseminação das suas informações. As novas tecnologias de informação e comunicação (TIC) foram capazes de romper barreiras e encurtar espaços, propiciando assim a colaboração na construção do conhecimento. Esse fato fez com que as relações humanas vivenciassem novos padrões de comunicabilidade refletindo-se em vários setores, principalmente na Educação.

O surgimento das novas TICs e a sua utilização crescente nos processos de ensinoaprendizagem fazem com que sejam repensadas novas estratégias didáticas para cursos presenciais e a distância. Sobre esse tema, Filatro e Piconez (2008, p. 2) concluem que

novas modalidades de educação, formais ou informais, individuais ou coletivas, de natureza autodidata ou sob a tutela de instituições de ensino, em formato presencial, híbrido ou totalmente mediado por tecnologias, vêm desenhando um novo cenário para a educação.

Nesse âmbito, surge o design instrucional ou desenvolvimento instrucional (DI), uma nova área de atuação ligada à Educação, mais precisamente à produção de materiais didáticos. Configura-se como uma metodologia que surgiu com as novas práticas do fazer pedagógico e colocam, agora, o aluno no centro do processo de ensinoaprendizagem. Sua história é muito próxima à da Educação a Distância (EaD), sendo, inicialmente, uma prática utilizada quase que exclusivamente nessa modalidade. O DI engloba conhecimentos dos campos de Design, Comunicação, Pedagogia e Tecnologia da Informação.

O designer instrucional é o profissional que aplica tal metodologia. Tem papel fundamental de cooperar com os professores, propondo as estratégias didáticas mais adequadas para a criação de objetos de aprendizagem e ambientes virtuais de aprendizagem (Roncarelli et al., 2010).

Observa-se, contudo, pouco material teórico (acadêmico e corporativo) que delineie e direcione as práticas dos profissionais que atuam nessa área. Com base nesse contexto, o presente trabalho vem apresentar reflexões sobre a fundamentação do design instrucional na EaD, bem como a sua efetiva aplicação para o êxito de cursos dessa modalidade. 


\section{O design instrucional no contexto da EaD}

Assim como observado no restante do mundo, a EaD no Brasil começou com cursos por correspondência, passou por uma evolução lenta utilizando tecnologias como rádio e televisão e hoje conta com um número cada vez maior de instituições que integram diferentes mídias na sua dispersão, com grande destaque para os recursos disponibilizados pela web 2.0.

Essa evolução fez com que novas maneiras de oferta de conteúdos instrucionais fossem repensadas, trazendo experiências inovadoras de aprendizagem para o perfil de educandos que surgiram a partir do aprimoramento das tecnologias da informação e comunicação. Surge então um novo olhar acerca dos processos cognitivos e das teorias de aprendizagem, gerando assim novas práticas reunidas sob a metodologia do design instrucional.

O design instrucional (DI) pode ser definido como o conjunto de atividades envolvidas na formulação de uma ação educativa. Assim, não é uma tarefa única, mas uma diversidade de práticas que permitem a construção de um produto educacional qualificado que atende não apenas às especificidades dos alunos quanto à orientação pedagógica da instituição (Filatro, 2008).

A metodologia do DI direciona suas ações na produção de materiais didáticos instrucionais que potencializem o aprendizado do aluno. Clareza e precisão dos conteúdos a serem passados, contextualização do assunto, significado para a vida prática, estratégias avaliativas eficazes e arquitetura da informação são pontos preconizados durante as ações de DI (Barreto et al., 2007).

\section{O processo de trabalho dentro do design instrucional}

Para Filatro (2008), o processo de trabalho no design instrucional se divide em cinco fases: análise, desenho, desenvolvimento, implementação e avaliação. Essas fases se organizam dentro do modelo ADDIE (do inglês: analysis, design, development, implementation e evaluation), formando uma cadeia contínua e cíclica que se retroalimenta ao final do processo.

Durante a primeira fase, a análise, é feita a coleta de informações, entendendo as necessidades do público-alvo. Essa fase gera um relatório de diagnóstico do curso a ser criado. Na fase do desenho, serão definidas todas as estratégias e ferramentas utilizadas no processo de aprendizagem, ou seja, tudo que deve ser produzido para que 
a oferta formativa seja executada e, assim, se possa estipular custos, profissionais envolvidos e cronograma de execução.

O produto final da fase de desenho é o projeto instrucional do curso, um documento que descreve todas as técnicas e ferramentas que serão elaboradas para o curso em questão e dará suporte à fase subsequente: o desenvolvimento. Nessa fase ocorre a produção propriamente dita do curso, que envolve a criação de todos os materiais didáticos necessários para sua execução. Ela representa a maior dedicação do designer instrucional, pois é nela que o profissional pode implementar toda a concepção pedagógica para garantir uma aprendizagem eficaz. Na fase de desenvolvimento são elaborados os conteúdos a serem ministrados, a mídias, o planejamento das disciplinas, as atividades avaliativas e a montagem da sala de aula virtual (dentro do ambiente virtual de aprendizagem).

A fase de implementação é o momento de execução do curso, no qual o aluno participará da experiência de aprendizagem, que, dependendo do modelo de DI (que será tratado mais adiante neste trabalho) implementado no curso, poderá contar com tutores e demais colegas de turma, compondo, assim, um grupo de colaboração para o aprendizado.

A última fase do processo é a avaliação. Durante essa fase é feita a comparação dos resultados planejados com os resultados obtidos ao final da oferta do curso, verificando se os objetivos do curso foram realmente alcançados. A avaliação é uma parte importante do processo pedagógico, pois é a partir dela que se evidenciam os pontos fortes e de melhoria para retroalimentar as fases de análise e desenho do curso. O feedback dado pela avaliação possibilita readequar, redirecionar ou reelaborar, se for preciso, as estratégias pedagógicas da oferta formativa. Portanto, a fase de avaliação cumpre também o objetivo de manutenção qualidade do curso e, por consequência, da instituição.

Podemos entender que as principais atividades do designer instrucional são relacionadas a desenvolver (ou redesenhar) projetos pedagógicos e instrucionais; acompanhar a criação e/ou avaliar os projetos instrucionais existentes. Esse profissional pode, ainda, atuar diretamente na feitura do curso ou coordenar uma equipe multidisciplinar; traçar meios para que o trabalho coletivo ocorra; qualificar e atualizar profissionais da área; atuar nos diversos processos de comunicação com a equipe. Ele deve demonstrar as competências pessoais para trabalhar em equipe, uma vez que não há desenho de ações educativas realizadas individualmente. 
Pelas características de organização do trabalho apresentadas, a metodologia do design instrucional é denominada, por alguns autores, "engenharia pedagógica" (Barros \& Santos, 2003; Oliveira \& Passerino, 2006; Milhomem, 2014), caracterizando-se por

um conjunto de princípios, de processos ou de tarefas que permitem definir o conteúdo de uma formação por meio de uma identificação estrutural de conhecimentos e de competências visadas, de realizar um cenário pedagógico de atividades de um curso, definindo o contexto de utilização e a estrutura dos materiais de aprendizagem (Gamez, 2004, p. 39, apud Oliveira \& Passerino, 2006).

Barros e Santos (2003) mencionam que o processo de engenharia pedagógica se preocupa também com o sistema de aprendizagem a ser elaborado, a identificação do problema de aprendizagem a ser solucionado, as mídias que devem ser utilizadas com vista a permitir a solução dos problemas iniciais, as operações ou processos que necessitam de apoio do mediador pedagógico (tutor) e a descrição dos requisitos do sistema de aprendizagem.

Batista e Menezes (2008) indicam ainda que o processo de design instrucional para a EaD possui, assim como o design, a intenção de ser um processo criativo, que busca solucionar problemas para os processos de ensino. Dessa forma, deve proporcionar êxito à instituição de ensino, garantindo preço e qualidade do serviço prestado ao aluno, denotando a eficiência da equipe de trabalho.

Dentre os produtos criados pelo designer instrucional podemos citar os modelos do plano de ensino/curso/treinamento, roteiros de conteúdo para a mídia impressa, mapas conceituais da disciplina/curso, desenho do ambiente de aprendizagem, roteiros para elaboração de vídeos, áudios, histórias em quadrinhos e animações e checklists de validação de conteúdos.

Vale ressaltar que o design instrucional é implementando por uma equipe multidisciplinar com competências ligadas à Pedagogia, à Psicologia, ao Design, à Gestão, à Computação e à Comunicação (Filatro, 2008). Para Roncarelli et al. (2010), os fatores que influenciam as ações de DI são: projeto gráfico, projeto político-pedagógico, orientações do curso, público-alvo e coordenação da produção de materiais didáticos.

Um DI é, assim, elaborado por meio do trabalho de uma equipe que traça os objetivos do curso a ser criado. O designer instrucional, portanto, é o profissional-chave dentro do processo de criação de um curso em EaD; como pode-se perceber, suas 
funções envolvem elaborar modelos para as ações pedagógicas, capacitar profissionais que elaboram conteúdos e demais membros da equipe e avaliar seu trabalho, roteirizar os conteúdos e pensar seu cronograma, elaborar os mapas conceituais, analisar as necessidades para uma aprendizagem de qualidade, desenhar o ambiente de aprendizagem e selecionar as tecnologias mais interessantes para ele, tudo de acordo com o perfil dos alunos, elaborar as avaliações diversas e acompanhar a construção dos materiais e ambientes, assim como validá-los.

Chaquime e Figueiredo (2013) afirmam que o designer instrucional tem o papel de integrar a equipe multidisciplinar na escolha das soluções tecnológicas mais apropriadas para promover a colaboração, cooperação, motivação e significação no aprendizado do aluno.

\section{O projeto instrucional}

Como citado anteriormente, o projeto instrucional é o documento norteador do processo de elaboração de um curso a distância; elaborado durante a fase de desenho. Ele se baseia nos objetivos da ação pedagógica após ser analisada a proposta educativa e o perfil dos alunos, avaliando todos os recursos necessários para desenvolver as melhores possibilidades de aprendizagem que garantam que o aluno possa construir seu conhecimento.

O projeto instrucional serve como guia, indicando o objetivo do curso, o perfil dos alunos, a proposta pedagógica, os recursos que serão disponibilizados, o pessoal envolvido na produção e a política institucional, dentre outros elementos. Esse documento é elaborado visando atender às necessidades dos alunos, acompanhando e avaliando os processos educacionais.

O projeto instrucional reflete o modelo de design instrucional que será aplicado na concepção do curso em questão. Para Filatro (2008), existem três modelos básicos de DI: fixo, aberto e contextualizado. Cada modelo reflete a forma como as estruturas do curso serão planejadas em relação à sua implementação. Ele deve considerar alguns pontos de vulnerabilidade para o curso, como os apresentados por Chaquime e Figueiredo (2013): público-alvo (limitações); motivação do aluno; acessibilidade; obsolescência da temática do curso (perecível). 
No DI fixo (ou DI fechado), as fases de desenvolvimento e implementação são bem definidas: o designer irá elaborar todas as mídias necessárias ao curso e planejar toda a interação antes de o curso ir ao ar, sem que haja necessidade de verificação de como o aluno reagirá ao longo do curso. Nesse modelo, o peso maior está no conteúdo do que será apresentado de forma fechada, sem se adequar às necessidades de estudo do aluno. Esse modelo aparece em cursos automatizados com feedbacks padronizados, por exemplo.

No DI aberto há maior sobreposição entre as fases de desenvolvimento e implementação. As estratégias e os materiais didáticos são previamente planejados, mas podem sofrer modificações ao longo da execução do curso, atendendo às necessidades dos alunos, conforme se desenrola a oferta formativa. Nesse modelo, os processos de aprendizagem são valorizados em detrimento dos produtos. Sendo assim, a fase de avaliação começa a ter maior valor, pois é a partir dos feedbacks dos alunos que as estratégias podem ser reelaboradas durante o período letivo.

O DI contextualizado (DIC) possui foco principal nos processos de aprendizagem, mas sem desconsiderar o uso de objetos de aprendizagem previamente elaborados. Filatro e Piconez (2004) dizem que esse modelo possibilita aos alunos um modo de estudo flexível, dando oportunidade de escolha de acordo com as demandas de aprendizado do público-alvo. Essas mesmas autoras apontam que, dentre as melhorias que o design instrucional contextualizado proporciona, pode-se citar:

- maior personalização aos estilos de aprendizagem e ritmos de estudo do aluno;

- adaptação às características regionais;

- acesso a informações e experiências vindas do ambiente externo ao curso;

- possibilidade de comunicação total entre os integrantes do curso, desde alunos até coordenadores;

- monitoramento automático da construção individual e coletiva de conhecimentos (Filatro \& Piconez, 2004).

Desta forma, o DIC pode ser comparado à imagem de um fractal, que se forma a partir de espiral, mostrando que os processos de planejamento e implementação estão inter-relacionados e cíclicos, proporcionando um aprimoramento constante do curso (Filatro \& Piconez, 2004). 


\section{Matriz instrucional}

No ano de 2007, o Ministério da Educação criou os Referenciais de Qualidade para a Educação Superior a Distância. Não se trata de lei ou decreto, mas apenas um guia que deve nortear a elaboração e a implementação do ensino a distância nas intuições de educação superior públicas e particulares.

Esse documento apresenta um conjunto de oito itens que indicam boas práticas para a execução de cursos na modalidade EaD: a concepção de educação e currículo no processo de ensino e aprendizagem; sistemas de comunicação; material didático; avaliação; equipe multidisciplinar; infraestrutura de apoio; gestão acadêmicoadministrativa; sustentabilidade financeira (MEC, 2007).

Dentre esses elementos, o sistema de comunicação, o planejamento dos materiais didáticos, os métodos de avaliação e parte do desenho curricular são especificados no documento denominado matriz instrucional.

A matriz instrucional é o documento elaborado para proporcionar o panorama do curso em questão, indicando os objetivos, os papéis de cada pessoa envolvida (aluno, tutor, coordenador), as atividades a serem realizadas, as durações e períodos de tempo, as ferramentas a serem utilizadas, os conteúdos a serem ministrados e os métodos de avaliação para as unidades de aprendizagem que compõem o curso ou disciplina (Filatro, 2008).

Portanto, a matriz instrucional deve ser elaborada na fase de desenvolvimento do curso, regendo-se pelo projeto instrucional e servindo de base para a produção dos materiais instrucionais do conteúdo a ser ministrado. Para sua elaboração, o designer instrucional pode se utilizar das seis perguntas fundamentais de bom texto: o quê? (conteúdo a ser ministrado); quem? (pessoas envolvidas nos processos de aprendizagem); quando? (tempos e momentos de estudo); onde? (ambientes para execução das tarefas de aprendizagem); como? (estratégias de ensino e métodos de avaliação); para quê? (objetivos de aprendizagem). Tais questionamentos evidenciam a forte relação entre os textos jornalísticos (precisos e diretos) com a linguagem utilizada no material instrucional. 


\section{A produção dos materiais didáticos}

Os materiais didáticos são produzidos na fase de desenvolvimento do curso, a partir do que foi delimitado pela matriz instrucional. Eles englobam os livros didáticos (mídia impressa), livros digitais (concepção igual ao impresso, mas veiculado digitalmente), vídeos, animações, materiais didáticos online (apresentações digitais pela web), simuladores, jogos e demais objetos de aprendizagem que foram planejados no projeto instrucional para serem usados no curso.

O material didático tem papel fundamental na busca pela autonomia do aluno. É ele que vai ser a porta de entrada do aluno da EaD. Ele, em suas formas impressa e digital, fará com que o aluno se encante ou não pelo conteúdo a ser apreendido.

A criatividade é a chave do sucesso. O material deve ser capaz de transmitir sua mensagem de forma clara e com toque artístico, envolvendo o espectador de forma ímpar, sem deixar de ser bem escrito e direcionado ao seu público específico.

A elaboração das diversas mídias requer do designer instrucional uma série de habilidades que garantam uma produção de materiais voltados para uma aprendizagem eficaz. Batista e Menezes (2008) apontam que

sabe-se que as mídias envolvidas são, além do MDI, vídeos, videoconferências, ambiente virtuais de aprendizagem e sistemas tutoriais inteligentes. Para o desenvolvimento de cada um desses materiais instrucionais, há a necessidade de competências específicas.

Portanto, o profissional que trabalha com DI deve possuir habilidades de redação clara e precisa, elaboração de arquitetura da informação eficiente, noções de design e ergonomia para materiais instrucionais, conhecimentos de Psicologia Cognitiva e criatividade.

Esses elementos irão compor a competência necessária para a criação de objetos de aprendizagem que permitirão ao aluno dar asas à sua imaginação e poder estudar de forma prazerosa. É importante ressaltar que o material didático não pode deixar partes sem explicação, sem a devida coesão, pois será motivo suficiente para dúvidas ou erros de interpretação. Dentro desse escopo, a dialogicidade e a interatividade devem estar presentes, sempre que possível, tornando a atividade educacional mais convidativa ao educando (Barreto et al., 2007). 


\subsection{Elaboração de livros didáticos}

Trabalhar a autonomia no aluno é uma das tarefas primordiais do material didático impresso (ou livro didático); é a forma que temos de instrumentalizá-lo para o ambiente fora do curso. Contudo, essa tarefa não é tão simples. Ao preparar um material rico e consistente, devemos garantir que a informação esteja disponibilizada de forma organizada, com fácil localização. É interessante que o material aguce a curiosidade do aluno em torno do conteúdo e estimule-o a realizar seus estudos. É muito importante que o material diferencie claramente o que é conteúdo substancial e quais são as sugestões para um conhecimento extra (conteúdo periférico) (Barreto et al., 2007).

O estabelecimento de prioridades é essencial para o sucesso, e estabelecer metas a serem atingidas é o fio condutor para que possamos saber qual a variedade de informações que serão disponibilizadas e quais as suas interconexões com o material didático e com materiais externos (como vídeos, livros e objetos virtuais).

O livro didático pode ser considerado uma vertente, um desdobramento ou mesmo uma especialização dentro do campo de DI. E, nesse sentido, capaz de representar grande parte das abordagens pedagógicas - pelo menos aquelas intencionais, objetivadas, mensuráveis - e diferentes modelos de DI, particularmente o DI contextualizado, uma vez que oferece mecanismos para flexibilização e contextualização das ações didáticas (Filatro \& Piconez, 2008, p. 8).

O principal ponto de atenção é ter o aluno como foco para poder criar um material com design didático que o envolva a aprender de forma colaborativa e faça com que ele desenvolva habilidades linguísticas que permitirão a ele relacionar-se, ler o mundo e submeter isso a todo o capital cultural que traz consigo.

\subsection{Roteirização para mídias digitais e ambiente virtuais}

O uso de tecnologias de comunicação digitais é cada vez mais difundido na EaD; as interfaces eletrônicas são ferramentas que possibilitam a interação e o aprendizado de forma compreensiva e diretiva.

Além de representarem poderosos recursos de apoio à aprendizagem, a utilização das TICs também fortalece um movimento recente dentro da teoria e prática do design instrucional que propõe a adoção de uma nova forma de planejar o ensino-aprendizagem (Filatro \& Piconez, 2008). 
Nesse escopo, destacam-se a produção do ambiente virtual de aprendizagem (AVA) e das mídias digitais, como animações, materiais didáticos online, animações, softwares simuladores, jogos e vídeos.

O material didático em formato digital incorpora recursos e vantagens, tais como: facilidade de replicação; disponibilidade de acesso; facilidade de atualização do conteúdo e diferentes formas de interatividade, que os materiais impressos não oferecem (Onari \& Yonezawa, 2014).

Gutierrez e Ulbricht (2009, apud Roncarelli et al., 2010) apontam que os materiais produzidos para a educação online devem ser acessíveis em forma e conteúdo, facilitando assim o processo de criação, análise e aplicação do conhecimento.

$\mathrm{Na}$ sala de aula online, conhecida como "ambiente virtual de aprendizagem" ou "plataforma de EaD", um curso ou uma aula podem abranger conteúdos de aprendizagem, propostas de trabalho e de avaliações e, no mesmo ambiente, dispor de interfaces de construção da comunicação e do conhecimento, tudo estruturado a partir de um desenho didático, isto é, da estrutura de apresentação do conjunto de conteúdos e de situações de aprendizagem compostos e dispostos estrategicamente de modo a serem utilizados pelo docente e pelos cursistas com a finalidade de potencializar a construção coletiva da comunicação, do conhecimento, da docência, da aprendizagem e da avaliação (Santos \& Silva, 2009).

A sala de aula virtual está aberta, precisando estar preparada para atender ao fluxo de informações e às relações entre os atores do curso na construção em rede do conhecimento. Nesse contexto, o designer instrucional é o profissional capacitado a projetar os materiais e as melhores formas de garantir a comunicação perfeita entre as partes (Roncarelli et al., 2010).

O designer instrucional não trabalha efetivamente na elaboração das mídias digitais e do AVA, mas é o responsável por projetar a sua elaboração a partir do conteúdo a ser ministrado. Após o projeto, ele deve acompanhar a produção da mídia pelo profissional que possui a habilidade específica na sua elaboração, como o editor de vídeo, o webdesigner, o programador etc. Para projetar a mídia, o designer instrucional elabora um documento denominado roteiro (ou storyboard). Nele, irá descrever, passo a passo, as especificações do objeto de aprendizagem.

Esse documento deve indicar, para vídeos, animações, simuladores e jogos, o tempo de duração, o conteúdo (em texto) a ser ministrado, os personagens (se existirem), as cenas, as imagens, os desafios, os esquemas e as funcionalidades para 
promoção da interatividade. Para a elaboração do AVA, o roteiro deve indicar a arquitetura da informação, os recursos do ambiente a serem usados (imagens, vídeos, links, tarefas) e os meios de comunicação entre os participantes.

Batista e Menezes (2008, p. 19) comentam que "ao designer instrucional é dada a tarefa de abordar e elaborar estratégias que consolidem uma relação benéfica entre a tecnologia e a educação, com uma aprendizagem colaborativa e autônoma". Complementando essa ideia, Roncarelli et al. (2010) indicam que o maior desafio do DI é garantir a qualidade da mediação pedagógica com ênfase nas necessidades dos usuários.

\section{Considerações finais}

A partir da análise feita sobre o material teórico pesquisado, pôde-se perceber a riqueza de aplicação do design instrucional como metodologia de trabalho. Essa riqueza não é fruto apenas das relações entre as teorias que embasam as suas ações, mas advém também das competências que o profissional designer instrucional precisa ter para propor estratégias de aprendizagem eficazes ao público-alvo de cursos a distância.

Ressalta-se que o profissional apto ao trabalho com design instrucional necessita de formação ampla e que traga habilidades de áreas como Comunicação, Design, Gestão de Processos e Pessoas, Pedagogia e Tecnologia da Informação. Tais habilidades trarão a competência necessária para a produção de materiais didáticos e ambientes de aprendizagem com foco nas necessidades do aluno.

Durante a construção de materiais instrucionais, deve ser priorizada uma linguagem clara, direta, precisa e objetiva, de forma a facilitar o processo de aprendizagem do aluno. Para isso, o entendimento do objetivo do curso, o desenho de suas estratégias e a avaliação contínua do processo são passos essenciais para a garantia da qualidade da oferta do curso.

Nesse sentido, a documentação de apoio às ações de design instrucional, tais como roteiro, storyboard, matriz instrucional, projeto instrucional e outros, é um importante suporte nas tomadas de decisão para a construção dos materiais didáticos e demais objetos de aprendizagem que compõem uma oferta formativa. 


\section{Referências bibliográficas}

Barreto, C. C. (Org.); Rodrigues, S., Carvalho, R. P. de, Rabelo, C. O., Fialho, A. P. A., \& Meyohas, J. (2007). Planejamento e elaboração de material didático impresso para educação a distância. Rio de Janeiro: Fundação Cecierj.

Barros, N. \& Santos, N. (2003). Engenharia pedagógica: a convergência tecnológica da Engenharia com a Pedagogia. In: COBENGE 2003: XXXI Congresso Brasileiro de Educação em Engenharia. Disponível em http://www.abenge.org.br/CobengeAnteriores/2003/artigos/EAD932.pdf

Batista, M. L. F. da S., \& Menezes, M. dos S. (2008). O design gráfico e o design instrucional na Educação a Distância. In: Design, arte e tecnologia. Bauru. Disponível em http://portal.anhembi.br/sbds/pdf/7.pdf

Chaquime, L. P., \& Figueiredo, A. P. S. (2013). O papel do designer instrucional na elaboração de cursos de educação a distância: exercitando conhecimentos e relatando a experiência. In: Congresso Brasileiro de Ensino Superior a Distância, Belém-PA. Disponível em http://www.aedi.ufpa.br/esud/trabalhos/poster/AT2/114065.pdf

Filatro, A. (2008). Design instrucional na prática. São Paulo: Pearson Education do Brasil.

Filatro, A., \& Piconez, S. C. B. (2004). Design instrucional contextualizado. In: Congresso ABED. Disponível em http://www.abed.org.br/congresso2004/por/htm/049-TCB2.htm

Filatro, A., \& Piconez, S. C. B. (2008). Contribuições do learning design para o design instrucional. In: Congresso ABED. Disponível em http://www.abed.org.br/congresso2008/tc/511200841151PM.pdf

MEC. Secretaria de Educação a Distância. (2007). Referenciais de qualidade Para Educação Superior a Distância. Disponível em http://portal.mec.gov.br/seed/arquivos/pdf/legislacao/refead1.pdf

Milhomem, M. (2014). Engenharia Pedagógica: a função e o trabalho do design instrucional. Paideia - Revista Científica de Educação a Distância, v. 5(9). Disponível em http://revistapaideia.unimesvirtual.com.br/index.php?journal=paideia\&page =article\&op=view\&path[]=322\&path[]=359 
Oliveira, E. M., \& Passerino, L. M. (2006). Uma arquitetura pedagógica baseada na diversidade de estratégias de ensino: proposta para o ensino técnico em informática. Novas Tecnologias na Educação, v. 4(2), p. 1-10.

Onari, D. Y., \& Yonezawa, W. M. (2014). O papel do design na produção de jogos digitais educacionais para o ensino de ciências. In: Coutinho, S. G.; Moura, M.; Campello, S. B.; Cadena, R. A.; Almeida, S. (eds.). Proceedings of the 6th Information Design International Conference, 5th InfoDesign, 6th Congic $[=$ Blucher Design Proceedings, num.2, vol.1]. São Paulo: Blucher.

Roncarelli, D., Motter, R. M. B., Obregon, R. F. A., Catapan, A. H., \& Cybis, A. (2010). Desafios e perspectivas do design instrucional: contexto sociotécnico, saberes e abordagens pedagógicas. In: II Seminário Nacional em Estudos da Linguagem: Diversidade, Ensino e Linguagem, Cascavel-PR.

Santos, E., \& Silva, M. (2009). Desenho didático para educação online. Em Aberto, Brasília, v. 22(79), p. 105-120. Disponível em http://emaberto.inep.gov.br/index.php/emaberto/article/viewFile/1437/1172 